\title{
FSI in Wind Turbines: A Review
}

\author{
https://doi.org/10.3991/ijes.v8i3.16595 \\ Yogesh Ramesh Patel \\ SP Pune University, Pune, India \\ yogeshpatel78270@gmail.com
}

\begin{abstract}
This paper affords a quick overview of the lookup inside the sphere of Fluid-structure interplay in Wind Turbines. Fluid-Structure Interaction (FSI) is the interaction of some movable or deformable shape with an inside or surrounding fluid flow. Flow prompted vibrations of two airfoils employed in turbine blades are investigated with the aid of using an effective coupled fluidstructure interaction approach. The method is based definitely on an often-happening Computational Fluid Dynamics (CFD) code that solves the Navier-Stokes equations described in Arbitrary Lagrangian-Eulerian (ALE) coordinates via the way of a finite extent method. The requirement for the FSI inside the turbine device is studied and comprehensively presented.
\end{abstract}

Keywords-Airfoils, CFD, Fluid-Structure interaction, Wind Turbines.

\section{Introduction}

A bendy strong structure contacting a flowing fluid is subjected to a strain which may additionally purpose deformation inside the structure. As a return, the deformed form alters the gliding field. The altered flowing field, in turn, exerts each different structure of stress on the shape with repeats of the method. this kind of interaction is named Fluid-Structure Interaction (FSI). To decide the penalties of fluid-structure interaction for a given system, the engineering graph often consists of super experimental testing. However, experiments can also moreover be costly, time-consuming, and in some instances even infeasible. As numerical fashions and techniques have matured over the final phrase a prolonged time to supply more correct predictions, and with the introduction of accelerating computing electrical energy for less costly prices, numerical simulation has ended up larger headquartered inside the sketch approach to information or possibly substitute experimental attempting out. [1,2].

\subsection{Fluid-structure interactions can be classified into three groups:}

1. Zero stress interactions: such as the transport of suspended solids in a liquid matrix.

2. Constant strain consistent float interactions: The consistent force exerted on an oilpipeline due to viscous friction between the pipeline walls and the fluid.

3. Oscillatory interactions: where the strain caused in the solid shape motives it to go such that the supply of strain is reduced, and the shape returns to its former state only for the procedure to repeat. 


\subsection{Typical applications of FSI:}

Biomedical functions - Drug shipping pumps, intravenous catheters, elastic artery modeling for stent design. [50].

Aerospace applications - Airfoil flutter and turbine engines.

Automotive purposes - Below hood cooling, HVAC heating/cooling, and warmth exchangers.

Fluid handling Applications - Valves, fuel injection components, and pressure regulators.

Civil engineering purposes - Wind and fluid loading of structures. Electronics cooling.

Wind generators are subjected to a challenging environment such as:

i. The atmospheric turbulence

ii. The floor boundary layer

iii. The rapid variants in wind speed and route

iv. The tower shadow for downwind turbine.

This stochastic inflow, related to the structure of the rotor ends up in a 3D unsteady aerodynamics and dynamic stall. The dynamic stall ends up in fluctuating blade pressure and blade oscillations referred to as aeroelastic phenomena. Problems of aeroelastic stability are regularly encountered on the new big turbine blades moreover as on the rotating turbine blades and parked turbine blades at wind speeds.

Most of the turbine aeroelastic analyses have carried out the utilization of engineering techniques the place the blade forces are often computed via the BEM notion and additionally the dynamic stall was once modeled with empirical fashions like the ONERA or the Beddoes-Leishman models. The dynamic response of the turbine used to be as soon as thereafter determined the use of structural computational gear $[5,7,9]$.

Most of the turbine aeroelastic analyses have carried out the utilization of engineering techniques the place the blade forces are many times computed thru the BEM idea and additionally the dynamic stall was once modeled with empirical fashions like the ONERA or the Beddoes-Leishman models. The dynamic response of the turbine used to be as soon as thereafter determined the use of structural computational gear $[11,56,58]$.

Displacements of the shape are then computed after convergence (or partial convergence) of the aerodynamic a section of the aeroelastic code. the problems of viscous fluid waft and elastic physique deformation have been then studied separately. These weakly coupled techniques are restricted to small deformations and low non-linearity. In most aeroelastic problems, the interplay between these two media and consequently the modeling of the unsteady aerodynamics and dynamic stall is of terrific significance for the aeroelastic balance study. we would like then to feature aeroelastic computations through the usage of the capability of a strongly coupled method with Fluid-Structure Interaction (FSI) techniques the place the aerodynamic forces are computed from the answer of the time-accurate Navier-Stokes equations and used for the reply of the rotor dynamic equations to work out the response of the shape at on every event step. FSI techniques are drastically employed in many industrial troubles [28] for aerospace 
functions the vicinity most papers are utilized to compressible flows. it is additionally been proven that the compressibility impact performs a limitless characteristic in aeroelastic balance limits. As windmills function in an incompressible environment, specific research has to be carried out for turbine blades. To the author's knowledge, the integral contribution with an FSI method utilized to turbine blades has been dole out inside the body of the ECU venture KnowBlade, the place Ellipsys3D, an in-residence Computational Fluid Dynamics (CFD) code, and a structural code are accustomed, simulate flap-lead/lag vibrations of a turbine blade. Recently, Svrcek et althe be instructed about the classical flutter the use of an FSI method the place the incompressible fluid equations had been solved with the aid of the finite component strategy the utilization of an Arbitrary Lagrangian-Eulerian (ALE) device of the Navier Stokes equations.

The intention of this learn about is to advocate an easy method to be used with standard laptop tools. A strategy is administrated in the course of a customer subroutine for the coupling of each code and for updating the grid. The viscous waft triggered vibrations on two airfoils are then simulated. First of all, the transferring mesh method is utilized to a compelled oscillating airfoil to take a look at the reliability of the CFD computations. Besides, for one case study, the distinction is created between laminar and turbulent computations administered with the answer of the Reynolds Averaged Navier-Stokes equations (RANS).

\section{$2 \quad$ Literature Review}

Santo et al (2020) carried out Computational Fluid Dynamics (CFD) evaluation of wind turbine blades with complete drawing and the small print of sub-system. The blade fabric is Cedarwood, sturdy, and mild weight. CAD mannequin of the blade profile the use of the Pro-E software program is created and the glide evaluation of the wind turbine blade mesh is created in the GAMBIT software. CFD evaluation of the wind turbine blade is carried out in the FLUENT software. Form this learn about they conclude as follows:

1. The value of numerical strength will increase as the attitude of assault will increase from zero to 70 , after 70 the price of numerical strength reduced. Hence the quintessential attitude of attack for this blade is 70 .

2. The most cost of the coefficient of overall performance (CPmax $=0.271)$ used to be noticed at the attitude of assault 70 and the pace of air eight $\mathrm{m} / \mathrm{s}$.

3. This blade can generate the most strength of $620 \mathrm{~W}$ at most $\mathrm{CP}$, the perspective of assault 70 , and the pace of air eight $\mathrm{m} / \mathrm{s}$.

4. From the sketch Fig 3.1, they used to be discovered that the coefficient of overall performance is will increase from three $\mathrm{m} / \mathrm{s}$ to eight $\mathrm{m} / \mathrm{s}$, and after eight $\mathrm{m} / \mathrm{s}$ price of the coefficient of overall performance decreased [1]. 


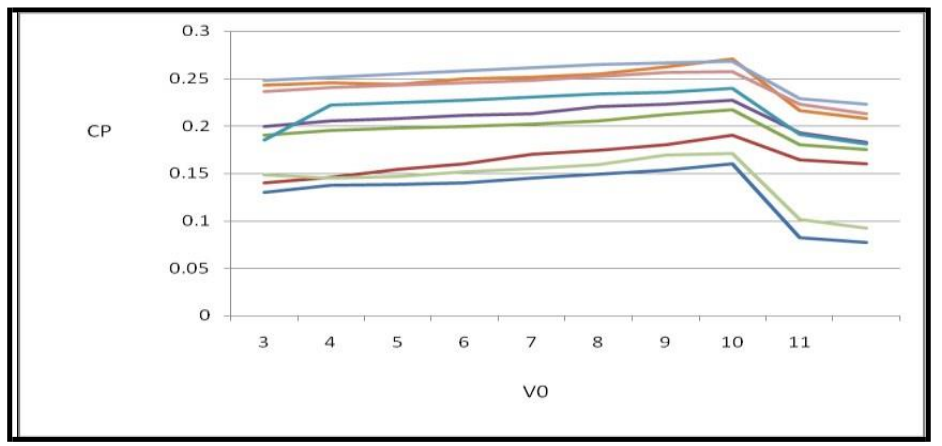

Fig. 1. Graph of CP versus V0

Wang, Y. G. et al (2020) create the 2D mannequin for the unsteady numerical simulation of VAWT using the FLUENT software program and algorithm SIMPLE blended with the sliding grid technology. For numerical simulation, it used two turbulence models. They use the NACA 0018 airfoil collection for created the blade 2D model. Domain $\mathrm{C}-\mathrm{H}$ kind for CFD evaluation $\mathrm{C}$ is a $1 / 2$ semicircle structure whose radius $=16 \mathrm{~m}$ \&amp; $\mathrm{H}$ is a rectangle whose measurement are $=32 \mathrm{~m} * 30 \mathrm{~m}$. In FLUENT they used several parameters for evaluation are Pressure, Velocity, Turbulent Kinetic Energy, Pressure Velocity Coupling, and Grid Generation. They use Standard k$\varepsilon$, RNG k- $\varepsilon$ as Turbulence Model. The consequences confirmed that the impact of distinctive turbulence fashions on the speed discipline is less, on the stress discipline is pretty large, and on the cost of the whole torque is a good deal large [4].

Kiani, A (2020) carried out the lookup of a VAWT the use of the NAC A0012-34 airfoil. The device was once modeled in Solid Works. They are the use of the STAR $\mathrm{CC}$ software to CFD analyzes the air flow around a vertical axis wind turbine to perform. Analysis has been done in three ways as show:

1. To decide CFD evaluation analyzed the 2D float over the chosen airfoil.

2. Determine the evaluation that appeared at the waft over a 3D illustration of the airfoil.

3. Finally, a full VAWT meeting used to be created and analyzed at more than a few wind instructions at equal wind speeds.

The airfoil than the 2D and 3D simulations used one-of-a-kind angles of assault (0 to 15 degrees) and speeds ( 15 \&amp; $30 \mathrm{mph}$ ) to determine. The full meeting protected three airfoils that had been connected into a $5 \mathrm{ft}$ high, three toes diameter structure. The outcomes of this lookup on the NACA 001234 airfoil confirmed it ought to be a very achievable preference for a residential VAWT. The 2D evaluation gave a stall attitude of about eight degrees, however, the 3D analysis, it being greater accurate, did now not supply us with a stall angle. The effects of the 3D full meeting evaluation of vertical axis wind turbines have been incomplete [8].

Nietiedt, S.et al (2020) had demonstrated the attainable of an incompressible Navier- Stokes CFD approach for the evaluation of horizontal axis wind turbines. The 
CFD consequences are validated in opposition to experimental information of the NREL energy overall performance trying out activities.

Comparisons are proven for the floor strain distributions at various prerequisites are exhibit as beneath taken:

a) Wind Velocity is $12.5 \mathrm{~m} / \mathrm{s}$.

b) Yaw Angle is $0^{\circ}$.

c) Rotational Speed is $25 \mathrm{rpm}$.

d) Turbulence Model is k- $\omega$ SST [14].

Wurm, F. H. et al (2019) had to learn about the optimization of aerodynamic diagram of wind turbine rotor blade via CFD with two instances one is Straight aspect blade and $2 \mathrm{~d}$ Swept facet blade. In this work, they discover the opportunity of growing the effectivity of the blades at greater wind speeds whilst preserving effectivity at the decrease wind speeds. They assemble one-of-a-kind area shapes to accomplish the analysis. For evaluation it makes use of distinct prerequisites in CFD solvers use as below show:

1. Wind Velocity is $5 \mathrm{~m} / \mathrm{s}$ to $25 \mathrm{~m} / \mathrm{s}$.

2. Reference Frame is moving.

3. Turbulence Model is k- $\omega$ use.

With these stipulations achieve a strain and stress contours. And they concluded stress contours in swept facet blade is higher than straight side blade. Swept side Blade produces higher electricity with greater wind velocity [17].

Bause, M. et al (2019) has pursuits to increase a sensible engineering methodology for the CFD-based evaluation of a couple of turbine installations. They are constructing the 2D experimental model of wind turbine which is of NREL S809 aerofoil collection and compared. Their effects with 3D CFD mannequin in XFoil 6.3 codes and two ANSYS CFX eleven versions. It creates the cylindrical area whose radius $2 \mathrm{~L}$ and size $5 \mathrm{~L}$ the place $\mathrm{L}=$ turbine radius. For the grid, technology makes use of ICEM-CFD (ANSYS) software. In evaluation, it uses the k- $\omega$ turbulence model. There are two major objectives for doing the evaluation is as below show:

- The primary aim is to predict the lift and drag for 2D experimental wind turbine.

- Its secondary aim is to compare the results of Lower CFD Fidelity to Higher CFD Fidelity model.

These two targets fulfill with one boundary circumstance which is to use strain as an inlet condition. The validation of CFD towards 2D blade sections confirmed that the CFD and XFOIL panel code over-predict height raise and have a tendency to underestimate stalled flow. The 3D effects in contrast nicely with the test over 4 running conditions. Results from the 3D corresponding calculated torque output confirmed a suitable settlement with the 3D CFD mannequin and experimental data. However, for excessive wind instances, the actuator mannequin tended to diverge from the CFD effects and test [28]. 
Liu, Q. et al (2019) have analyzed the impact of wind turbine blade tip geometry numerically the use of Computational Fluid Dynamics (CFD). The researcher takes three exclusive rotating blade pointers are in contrast for connected glide stipulations and the glide physics round the geometries are analyzed. For evaluation, they use the FLUENT 6.2 model with k- $\omega$ SST turbulence model. They bought stress coefficient, thrust, and torque for three guidelines with a rotational pace of $71.9 \mathrm{rpm}$ and wind velocity $7 \mathrm{~m} / \mathrm{s}, 8.5 \mathrm{~m} / \mathrm{s}$. Its consequences from the evaluation that a higher tip form that produced higher torque to thrust ratios in each force and moments is a geometry that has the cease tip at the pitch axis. The work right here introduced indicates that CFD might also show to be beneficial to complement $2 \mathrm{D}$ based techniques on the layout of new wind turbine blade pointers [31].

Birken, P et al (2018) has work completed on 3D Navier-Stokes computations of a stall-regulated wind turbine developed at the ONERA software program in the discipline of CFD simulations of the glide subject round wind turbine blades. The compressible a Navier-Stokes solver has been used to compute 2D and 3D configurations of a 2bladed wind turbine. Prediction of the S809 airfoil overall performance is mentioned and turbulence mannequin is k- $\omega$ SST. 3D computations are then presented, analyzed, and in contrast to the experimental outcomes [46].

\section{Theoretical Model for Predicting FSI}

\subsection{Beam model}

The beam mannequin is greater effortlessly solved for complicated pipe systems. Moreover, smaller pipes have thickness-to-diameter ratios above the thin-wall idea restrict [65]. Almost all sensible pipe structures have complicated form and boundary stipulations consequently beam mannequin is extensively time-honored and adopted.

There are two beam models, Euler-Bernoulli beam mannequin and Timoshenko beam model. The theoretical fashions based totally on beam fashions mostly consist of the four-equation model, six-equation model, eight-equation model, twelve-equation model, and fourteen-equation model. These fashions are solely relevant for the lowfrequency acoustic conduct of linearly elastic, fluid-filled pipes of round cross-section [10]. An eight-equation mannequin approves for axial (longitudinal) and lateral (flexural) wave propagation alongside every pipe in the device $[35,62]$. The FSI four-equation mannequin of liquid-filled pipe structures is a set of coupled linear first-order partial differential equations.

\subsection{Other model}

Hadj-Taïeb, L.; Has prolonged a Vaporous Bubbly Cavitating Flow Model developed via Hadj-Täleb to find out about fluid-structure interplay in transient flows in elastic pipes with vapor cavitations $[17,60]$ has mounted the sectional lumped parameter mannequin of the FSI axial motion of straight fluid-filled pipe. [14] has developed the equations of the lateral and axial movement of the pipe conveying fluid by 
Hamilton's precept beneath the circumstance of FSI to learn about pipe conveying fluid below the exchange of liquid stress as nicely as viscosity and gravity. Many scientist have simulated incompressible fluid go with the flow in a pipe the use of RANS (Reynolds-Averaged-Navier-Stokes) equation alongside with continuity and momentum equation for the glide to learn about outcomes of special parameters of three-limb pipe on drift characteristics, shear stress distribution and deformation of pipe [58] and impact of a number parameters of elbow pipe on go with the flow feature, erosion rate, and deformation of the elbow.

\section{$4 \quad$ Numerical Method for Solving FSI Model}

For the numerical simulations, a unique finite difficulty scheme is used thinking about such a method is extra splendid than implicit techniques for non-linear quick transient dynamics. Fluid-structure interaction (FSI) phenomena ought to moreover be viewed for the calculation of the outcomes of the explosive waves onto the structure. This part affords a range of the wonderful techniques utilized to deal with numerous peculiarities that show up inside the simulation of explosion scenarios, like the modeling of the airwave, the non-conforming FSI formulation, and consequently the modeling of the glazing parts. one amongst the important drastically used techniques of fixing the above equations is that the Finite Volume Method $[40,56]$.

\subsection{Finite volume method}

Finite Volume Method transforms the differential equations into algebraic equations with the aid of way of the alternate of integration area from the whole manipulate extent to the diploma of one cell. the aggregate indoors boundary of one cellular telephone is dole out primarily based on given approximation of variability of parameters describing the waft inside the volume. The fluid is seen as a continuum. When inspecting the waft on the macro scale, the molecular form has an impact on is neglected. The fluid description makes use of the macroscopic state variables like pressure, velocity, density, temperature, and time and residence derivatives. generally, these variables inside the given basic place of fluid's extent take the familiar cost from an ample variety of fluid particles. Its functionality that an integral area of fluid extent is that the smallest possible part, inside which the averaged macroscopic united states of America variables are now not any longer barring extend related to singular molecules [50]. Children with autism are frequently very imitative inside the vocal discipline and from time to time repeat what they want been instructed (echolalia) instead of answering [13]. But when these individuals provide answers, they may be insufficient on problems that will no longer be acquainted with them and typically they shall now not grant all the required records to the interlocutor to obtain appropriate communication. Difficulty in a narration has additionally been found [14]. Moreover, they're regularly limited to monologues, as an alternative than being interested through reciprocal verbal transactions. 
Independently of the used method, the most necessary is the mathematical equations describing the fluid behavior. Those equations are derived from simple bodily principles, such as:

- The precept of conservation of mass (the continuity equation), which says that the velocity of mass amplify is equal to the price of mass injected to the object.

- The precept of conservation of momentum, regular with Newton's 2nd regulation of motion, says that the exchange in the momentum of a particle of fluid is equal to the forces utilized on the particle.

- The precept of conservation of electricity primarily based on the first regulation of thermodynamics says that the fee of exchange of fluid-particle is equal to the supplied heat and the resultant of work executed on the particle.

\section{Experimental Validation}

Besides theoretical fashions and numerical options authors additionally developed or used experimental setup of wind Turbines and wind turbines diffusers to validate respective the mathematical fashions for the fluid-structure interplay between the Solid area and fluid flowing over it. The vary of techniques of lookup wishes to be validated towards this with experimental data. The first step that wishes to be doling out to complete the drift evaluation ought to be a waft region development. it is a kind of digital aerodynamic tunnel, for the duration of which the analyzed object is placed. The area consists of awesome zones.

The outer quarter is that the area spherical the examined object, which desires to be huge adequate to now not disturb the floating indoors of the internal zones. A bodily phenomenon indoors the realm is a common spherical of the examined object. The layer is fashioned of very skinny elements, which make bigger in dimension due to the fact the distance from the object increases. The layer is fashioned to accommodate the phenomena related to fluid viscosity, performing inside the closest proximity between the fluid and examined object, the vicinity extensive fluid glide speed gradients can occur.

\section{Summary}

Fluid-Structure Interaction ought to be a new multidisciplinary branch that offers with concurrent come across out about of fluid and structure domain. Structural electricity inside the FSI is determined resolutely to be the predominant researched problem. to increase a mathematical model Timoshenko beam thinking is notably usually happening and adopted to decorate new fashions with the aid of exquisite stipulations for the FSI problem. as an alternative than the beam, the idea researcher developed a particular mathematical model for the precise hassle of interest. Most of the classical issues with fluid-structure interplay are solved with the useful resource of the utilization of the FVM technique all through which approach Fluid area contrast (CFD) is administrated and consequently the results are in addition to structural contrast as a load condition. 


\section{$7 \quad$ References}

[1] Santo, G., Peeters, M., Van Paepegem, W., \& Degroote, J. (2020). Fluid-Structure Interaction Simulations of a Wind Gust Impacting on the Blades of a Large Horizontal Axis Wind Turbine. Energies, 13(3), 509. https://doi.org/10.3390/en13030509

[2] Boujleben, A., Ibrahimbegovic, A., \& Lefrançois, E. (2020). An efficient computational model for fluid-structure interaction in application to large overall motion of wind turbine with flexible blades. Applied Mathematical Modelling, 77, 392-407. https://doi.org/10. 1016/j.apm.2019.07.033

[3] Peralta, G., \& Kunisch, K. (2020). Analysis and finite element discretization for optimal control of a linear fluid-structure interaction problem with delay. IMA Journal of Numerical Analysis, 40(1), 140-206. https://doi.org/10.1093/imanum/dry070

[4] Trifunović, S., \& Wang, Y. G. (2020). Existence of a weak solution to the fluid-structure interaction problem in 3D. Journal of Differential Equations, 268(4), 1495-1531. https:// doi.org/10.1016/j.jde.2019.09.002

[5] Amin, M. M., \& Kiani, A. (2020). Multi-Disciplinary Analysis of a Strip Stabilizer using Body-Fluid-Structure Interaction Simulation and Design of Experiments (DOE). Journal of Applied Fluid Mechanics, 13(1), 261-273. [53] https://doi.org/10.29252/jafm.13.01.30253

[6] Amin, M. M., \& Kiani, A. (2020). Multi-Disciplinary Analysis of a Strip Stabilizer using Body-Fluid-Structure Interaction Simulation and Design of Experiments (DOE). Journal of Applied Fluid Mechanics, 13(1), 261-273. https://doi.org/10.29252/jafm.13.01.30253

[7] Shkara, Y., Cardaun, M., Schelenz, R., \& Jacobs, G. (2020). Aeroelastic response of a multimegawatt upwind horizontal axis wind turbine (HAWT) based on fluid-structure interaction simulation. Wind Energy Science, 5(1), 141-154. https://doi.org/10.5194/wes-5-141-2020

[8] Amin, M. M., \& Kiani, A. (2020). Multi-Disciplinary Analysis of a Strip Stabilizer using Body-Fluid-Structure Interaction Simulation and Design of Experiments (DOE). Journal of Applied Fluid Mechanics, 13(1), 261-273. https://doi.org/10.29252/jafm.13.01.30253

[9] Boujleben, A., Ibrahimbegovic, A., \& Lefrançois, E. (2020). An efficient computational model for fluid-structure interaction in application to large overall motion of wind turbine with flexible blades. Applied Mathematical Modelling, 77, 392-407. https://doi.org/10.10 16/j.apm.2019.07.033

[10] Amin, M. M., \& Kiani, A. (2020). Multi-Disciplinary Analysis of a Strip Stabilizer using Body-Fluid-Structure Interaction Simulation and Design of Experiments (DOE). Journal of Applied Fluid Mechanics, 13(1), 261-273. https://doi.org/10.29252/jafm.13.01.30253

[11] Yang, Y., Liao, H., Xu, Y., Yang, S., \& Niu, J. (2019). Coupled fluid-structure simulation of a vibration-assisted rotary percussion drilling tool. Energy Sources, Part A: Recovery, Utilization, and Environmental Effects, 41(14), 1725-1738. https://doi.org/10.1080/155670 $\underline{36.2018 .1549147}$

[12] Ullah, H., Hussain, M., Abbas, N., Ahmad, H., Amer, M., \& Noman, M. (2019). Numerical investigation of modal and fatigue performance of a horizontal axis tidal current turbine using fluid-structure interaction. Journal of Ocean Engineering and Science, 4(4), 328-337. https://doi.org/10.1016/i.joes.2019.05.008

[13] Shi, F., Wang, Z., Zhang, J., Gong, Z., \& Guo, L. (2019). Influences of wind and rotating speed on the fluid-structure interaction vibration for the offshore wind turbine blade. Journal of Vibroengineering, 21(2), 483-497. https://doi.org/10.21595/jve.2018.19356

[14] Nietiedt, S., Goering, M., Willemsen, T., Wester, T. T. B., Kröger, L., Guelker, G., \& Luhmann, T. (2019). Measurement of Fluid-Structure Inter-Action of Wind Turbines In Wind Tunnel Experiments: Concept And First Results. International Archives of the 
Photogrammetry, Remote Sensing \& Spatial Information Sciences. https://doi.org/10.5194/isprs-archives-xlii-2-w18-143-2019

[15] Badshah, M., Badshah, S., VanZwieten, J., Jan, S., Amir, M., \& Malik, S. A. (2019). Coupled Fluid-Structure Interaction Modelling of Loads Variation and Fatigue Life of a FullScale Tidal Turbine under the Effect of Velocity Profile. Energies, 12(11), 2217. https:// doi.org/10.3390/en12112217

[16] Zhu, R., Chen, D. D., \& Wu, S. W. (2019). Unsteady Flow and Vibration Analysis of the Horizontal-Axis Wind Turbine Blade under the Fluid-Structure Interaction. Shock and Vibration, 2019. https://doi.org/10.1155/2019/3050694

[17] Laß, A., Schilling, M., Kumar, J., \& Wurm, F. H. (2019). Rotor dynamic analysis of a tidal turbine considering fluid-structure interaction under shear flow and waves. International Journal of Naval Architecture and Ocean Engineering, 11(1), 154-164. https://doi.org/10. 1016/j.ijnaoe.2018.03.002

[18] Li, Z., Wang, Y., Li, T., Liu, F., \& Ji, J. (2019). The dynamic characteristics of the ultimate strength of a turbine runner blade under hydraulic excitation. Energy Sources, Part A: Recovery, Utilization, and Environmental Effects, 41(24), 3127-3137. https://doi.org/10.10 $\underline{80 / 15567036.2019 .1586014}$

[19] Papoulias, G., Nousias, S., \& Moustakas, K. (2019, July). Fluid-structure interaction simulation framework for cerebral aneurysm wall deformation. In 2019 10th International Conference on Information, Intelligence, Systems and Applications (IISA) (pp. 1-7). IEEE. https://doi.org/10.1109/iisa.2019.8900781

[20] Rahmani, S., Jarrahi, A., Saed, B., Navidbakhsh, M., Farjpour, H., \& Alizadeh, M. (2019). Three-dimensional modeling of Marfan syndrome with elastic and hyperelastic materials assumptions using fluid-structure interaction. Bio-medical materials and engineering,30(3), 255-266. https://doi.org/10.3233/bme-191049

[21] Mahmoud, A. H., Hassan, N., \& Mahmoud, A. M. (2019, July). Three-dimensional fluid structure interaction analysis of carotid artery models with different calcification patterns. In 2019 41st Annual International Conference of the IEEE Engineering in Medicine and Biology Society (EMBC) (pp. 7019-7022). IEEE. https://doi.org/10.1109/embc.2019.8856 $\underline{813}$

[22] Fournié, M., Ndiaye, M., \& Raymond, J. P. (2019). Feedback stabilization of a two-dimensional fluid-structure interaction system with mixed boundary conditions. SIAM Journal on Control and Optimization, 57(5), 3322-3359. https://doi.org/10.1137/18m1172405

[23] Li, S., Li, R., Wang, Z., Xu, D., Yan, Y., Xu, Y., \& Chen, X. (2019). Fluid-Structure Interaction Vibration Response Analysis of the Hydrocyclone Under Periodic Excitation. IEEE Access, 7, 146273-146281. https://doi.org/10.1109/access.2019.2945837

[24] Ren, Z., Wang, Z., Stern, F., Judge, C., \& Ikeda-Gilbert, C. (2019). Vertical Water Entry of a Flexible Wedge into Calm Water: A Fluid-Structure Interaction Experiment. Journal of Ship Research, 63(1), 41-55. https://doi.org/10.5957/josr.09180087

[25] Zhang, Qiwei, Xiangdong Kong, Zhipeng Huang, Bin Yu, and Guo Meng. "Fluid-structureinteraction analysis of an aero hydraulic pipe considering friction coupling." IEEE Access 7 (2019): 26665-26677. https://doi.org/10.1109/access.2018.2890442

[26] Govindarajua, K., Hegdea, P., Badruddinb, I. A., \& Alsharifa, I. O. A. M. (2019, March). Fluid Structure Interaction Simulation Study of Travelling Wave Valve-less Micro Pump in Fluid Delivery. In 2019 Advances in Science and Engineering Technology International Conferences (ASET) (pp. 1-5). IEEE. https://doi.org/10.1109/icaset.2019.8714211

[27] Zhang, Z. L., T. Long, J. Z. Chang, and M. B. Liu. "A smoothed particle element method (SPEM) for modeling fluid-structure interaction problems with large fluid deformations." 
Computer Methods in Applied Mechanics and Engineering 356 (2019): 261-293. https://doi.org/10.1016/j.cma.2019.07.024

[28] Hai, B. S. M. E., \& Bause, M. (2019). Numerical study and comparison of alternative time discretization schemes for an ultrasonic guided wave propagation problem coupled with fluid-structure interaction. Computers \& Mathematics with Applications, 78(9), 2867-2885. https://doi.org/10.1016/j.camwa.2019.01.009

[29] Nazari, T., Rabiee, A., \& Kazeminejad, H. (2019). Two-way fluid-structure interaction simulation for steady-state vibration of a slender rod using URANS and LES turbulence models. Nuclear Engineering and Technology, 51(2), 573-578. https://doi.org/10.1016/j. net.2018.10.011

[30] Govindarajua, K., Hegdea, P., Badruddinb, I. A., \& Alsharifa, I. O. A. M. (2019, March). Fluid Structure Interaction Simulation Study of Travelling Wave Valve-less Micro Pump in Fluid Delivery. In 2019 Advances in Science and Engineering Technology International Conferences (ASET) (pp. 1-5). IEEE. https://doi.org/10.1109/icaset.2019.8714211

[31] Xu, Y., Yu, C., Liu, F., \& Liu, Q. (2019). A coupled NMM-SPH method for fluid-structure interaction problems. Applied Mathematical Modelling, 76, 466-478. https://doi.org/10.10 16/j.apm.2019.06.020

[32] Hundertmark-Zaušková, A. (2019). On the convergence of fixed point iterations for the moving geometry in a fluid-structure interaction problem. Journal of Differential Equations, 267(12), 7002-7046. https://doi.org/10.1016/j.jde.2019.07.009

[33] Ali, H., Kim, K. W., Bang, S. G., Chae, H. B., Shin, S. W., \& Park, C. W. (2019). Numerical modeling of fluid-structure interaction between sewage water flow and bar screen to improve the screening process. Water and Environment Journal, 33(4), 560-573. https:// doi.org/10.1111/wej.12427

[34] Valsamos, G., Casadei, F., Solomos, G., \& Larcher, M. (2019). Risk assessment of blast events in a transport infrastructure by fluid-structure interaction analysis. Safety science, 118, 887-897. https://doi.org/10.1016/j.ssci.2019.06.014

[35] Faizal, W. M., Ghazali, N. N. N., Badruddin, I. A., Zainon, M. Z., Yazid, A. A., Ali, M. A. B., \& Razi, R. M. (2019). A review of fluid-structure interaction simulation for patients with sleep related breathing disorders with obstructive sleep. Computer methods and programs in biomedicine, 105036. https://doi.org/10.1016/j.cmpb.2019.105036

[36] Valsamos G, Casadei F, Solomos G, Larcher M. Risk assessment of blast events in a transport infrastructure by fluid-structure interaction analysis. Safety science. 2019 Oct 1; 118:887-97. https://doi.org/10.1016/j.ssci.2019.06.014

[37] Hai, B. S. M. E., \& Bause, M. (2019). Numerical study and comparison of alternative time discretization schemes for an ultrasonic guided wave propagation problem coupled with fluid-structure interaction. Computers \& Mathematics with Applications, 78(9), 2867-2885. https://doi.org/10.1016/j.camwa.2019.01.009

[38] Nazari, T., Rabiee, A., \& Kazeminejad, H. (2019). Two-way fluid-structure interaction simulation for steady-state vibration of a slender rod using URANS and LES turbulence models. Nuclear Engineering and Technology, 51(2), 573-578. https://doi.org/10.1016/j. net.2018.10.011

[39] Zhu, R., Chen, D. D., \& Wu, S. W. (2019). Unsteady Flow and Vibration Analysis of the Horizontal-Axis Wind Turbine Blade under the Fluid-Structure Interaction. Shock and Vibration, 2019. https://doi.org/10.1155/2019/3050694

[40] Nazari, T., Rabiee, A., \& Kazeminejad, H. (2019). Two-way fluid-structure interaction simulation for steady-state vibration of a slender rod using URANS and LES turbulence models. Nuclear Engineering and Technology, 51(2), 573-578. https://doi.org/10.1016/j. $\underline{\text { net.2018.10.011 }}$ 
[41] Gilmanov, A., Barker, A., Stolarski, H., \& Sotiropoulos, F. (2019). Image-Guided FluidStructure Interaction Simulation of Transvalvular Hemodynamics: Quantifying the Effects of Varying Aortic Valve Leaflet Thickness. Fluids, 4(3), 119. https://doi.org/10.3390/fluids4030119

[42] Hai, B. S. M. E., \& Bause, M. (2019). Numerical study and comparison of alternative time discretization schemes for an ultrasonic guided wave propagation problem coupled with fluid-structure interaction. Computers \& Mathematics with Applications, 78(9), 2867-2885. https://doi.org/10.1016/j.camwa.2019.01.009

[43] Zhu, R., Chen, D. D., \& Wu, S. W. (2019). Unsteady Flow and Vibration Analysis of the Horizontal-Axis Wind Turbine Blade under the Fluid-Structure Interaction. Shock and Vibration, 2019. https://doi.org/10.1155/2019/3050694

[44] Badshah, M., Badshah, S., \& Kadir, K. (2018). Fluid Structure Interaction Modelling of Tidal Turbine Performance and Structural Loads in a Velocity Shear Environment. Energies, 11(7), 1837. https://doi.org/10.3390/en11071837

[45] Haq, M. U., \& Gang, Z. (2018, January). Computational fluid dynamics analysis of IPMC actuated mechanical fin through two-way fluid structure inter-action approach. In 2018 15th International Bhurban Conference on Applied Sciences and Technology (IBCAST) (pp. 585-592). IEEE. https://doi.org/10.1109/ibcast.2018.8312284

[46] Monge, A., \& Birken, P. (2018). On the convergence rate of the Dirichlet-Neumann iteration for unsteady thermal fluid-structure interaction. Computational Mechanics, 62(3), 525-541. https://doi.org/10.1007/s00466-017-1511-3

[47] Gholampour, S., \& Jalali, A. (2018). Thermal analysis of the dentine tubule under hot and cold stimuli using fluid-structure interaction simulation. Biomechanics and modeling in mechanobiology, 17(6), 1599-1610. https://doi.org/10.1007/s10237-018-1046-3

[48] Calderer, A., Guo, X., Shen, L., \& Sotiropoulos, F. (2018). Fluid-structure interaction simulation of floating structures interacting with complex, large-scale ocean waves and atmospheric turbulence with application to floating offshore wind turbines. Journal of Computational Physics, 355, 144-175. https://doi.org/10.1016/j.jcp.2017.11.006

[49] Spühler, Jeannette H., Johan Jansson, Niclas Jansson, and Johan Hoffman. "3D fluid-structure interaction simulation of aortic valves using a unified continuum ALE FEM model." Frontiers in physiology 9 (2018): 363. https://doi.org/10.3389/fphys.2018.00363

[50] Zhao, X., Yang, X., Yu, L., Liu, X., \& Wang, J. (2018). Study of minimal effective reefing ratio based on an empirical formula and fluid-structure-interaction method. Aviation,22(4), 136-142. https://doi.org/10.3846/aviation.2018.6804

[51] Haq, M. U., \& Gang, Z. (2018, January). Computational fluid dynamics analysis of IPMC actuated mechanical fin through two-way fluid structure interaction approach. In 2018 15th International Bhurban Conference on Applied Sciences and Technology (IBCAST) (pp. 585-592). IEEE. https://doi.org/10.1109/ibcast.2018.8312284

[52] Zhao, X., Yang, X., Yu, L., Liu, X., \& Wang, J. (2018). Study of minimal effective reefing ratio based on an empirical formula and fluid-structure-interaction method. Aviation,22(4), 136-142. https://doi.org/10.3846/aviation.2018.6804

[53] Gholampour, S., \& Jalali, A. (2018). Thermal analysis of the dentine tubule under hot and cold stimuli using fluid-structure interaction simulation. Biomechanics and modeling in mechanobiology, 17(6), 1599-1610. https://doi.org/10.1007/s10237-018-1046-3

[54] Chen, M., Shu, D., Jiang, J., \& Wu, J. (2017, December). Study on calculation of pressure wave speed with fluid-structure interaction in assembled pipelines. In 2017 14th Inter-national Computer Conference on Wavelet Active Media Technology and Information Processing (ICCWAMTIP) (pp. 233-238). IEEE. https://doi.org/10.1109/iccwamtip.2017.830 $\underline{1486}$ 
[55] Liang, L., Wanyan, Z., Xu, J., Nie, R., \& Du, X. (2017, October). Study on data transferring in fluid structure interaction for launching vehicle. In 2017 IEEE International Con-ference on Unmanned Systems (ICUS) (pp. 554-560). IEEE. https://doi.org/10.1109/icus. $\underline{2017.8278407}$

[56] Liang, Lei, Zhenhai Wanyan, Jia Xu, Rongmei Nie, and Xiaoxue Du. "Study on data transferring in fluid structure interaction for launching vehicle." In 2017 IEEE International Conference on Unmanned Systems (ICUS), pp. 554-560. IEEE, 2017. https://doi.org/10. 1109/icus.2017.8278407

[57] Ageze, M. B., Hu, Y., \& Wu, H. (2017). Comparative Study on Uni-and Bi-Directional Fluid Structure Coupling of Wind Turbine Blades. Energies, 10(10), 1499. https://doi.org/ $\underline{10.3390 / e n 10101499}$

[58] Damaziak, K., Małachowski, J., \& Tomaszewski, M. (2016, October). Numerical analysis of small wind turbine diffusor using fluid structure interaction. In IECON 2016-42nd Annual Conference of the IEEE Industrial Electronics Society (pp. 5556-5561). IEEE. https:// doi.org/10.1109/iecon.2016.7793165

[59] Zhang, Jianping, Wenlong Chen, Tingjun Zhou, Helen Wu, Danmei Hu, and Jianxing Ren. "Analysis of dynamic stability for wind turbine blade under fluid-structure interaction." Journal of Vibroengineering 18, no. 2 (2016): 1175-1186.

[60] F. Moukalled, F. Mangani, M. Darwish, "The Finite Volume Method in Computional Fluid Dynamics", Springer, 2015

[61] Wang, Z. K., Tsai, G. C., \& Yi-Bao, C. (2014). One-way fluid-structure interaction simulation of an offshore wind turbine. International Journal of Engineering and Technology Innovation, 4(3), 127.

[62] Wang, Z. K., Tsai, G. C., \& Yi-Bao, C. (2014). One-way fluid-structure interaction simulation of an offshore wind turbine. International Journal of Engineering and Technology Innovation, 4(3), 127.

[63] Ramdan, D., Harahap, U., \& Abdillah, M. Z. (2013, June). Fluid structure interaction simulation in IC encapsulation process. In 2013 International Conference on QiR (pp. 220-225). IEEE. https://doi.org/10.1109/qir.2013.6632568

[64] Ramdan, D., Harahap, U., \& Abdillah, M. Z. (2013, June). Fluid structure interaction simulation in IC encapsulation process. In 2013 International Conference on QiR (pp. 220-225). IEEE. https://doi.org/10.1109/qir.2013.6632568

[65] Khalid, S. S., Zhiguang, J., Fuding, T., Liang, Z., \& Chaudhry, A. Z. (2013, January). CFD simulation of vertical axis tidal turbine using two-way fluid structure interaction method. In Proceedings of 2013 10th International Bhurban Conference on Applied Sciences \& Technology (IBCAST) (pp. 286-291). IEEE. https://doi.org/10.1109/ibcast.2013.6512167

[66] Khalid, Syed Shah, Jin Zhiguang, Tang Fuding, Zhang Liang, and Ahmad Zamir Chaudhry. "CFD simulation of vertical axis tidal turbine using two-way fluid structure inter-action method." In Proceedings of 2013 10th International Bhurban Conference on Applied Sciences \& Technology (IBCAST), pp. 286-291. IEEE, 2013. https://doi.org/10.11 09/ibcast.2013.6512167

[67] Ong, C. W., Bee Ting Chan, E. Lim, NA Abu Osman, A. A. Abed, Socrates Dokos, and Nigel H. Lovell. "Fluid structure interaction simulation of left ventricular flow dynamics under left ventricular assist device support." In 2012 Annual International Conference of the IEEE Engineering in Medicine and Biology Society, pp. 6293-6296. IEEE, 2012. https://doi.org/10.1109/embc.2012.6347433

[68] Z. Yun, Y. Hui, (2011), "Coupled fluid structure flutter analysis of a transonic fan", Chinese Journal of Aeronautics, vol.24, 2011, 258-264. https://doi.org/10.1016/s10009361 (11)60031-9 
[69] Svacek P., Feistauer M. and Horacek J., 2007, Numerical simulation of flow induced airfoil vibrations with large amplitudes, J. Fluids and Structures, vol. 23, pp. 391- 411. https:// doi.org/10.1016/j.jfluidstructs.2006.10.005

[70] Hansen, M.O.L., Sorensen, J.N., Voutsinas, S., Sorensen, N. and Madsen, H.Aa., State of the art in wind turbines aerodynamics and aeroelasticity, 2006, Progress in Aero-space Sciences, vol. 42, pp. 285-330. https://doi.org/10.1016/j.paerosci.2006.10.002

[71] Larsen T.J., Bertagnolio F., Johansen J., Madsen H.A., Bak C. and Hansen A.M., 2003, Present Status of Aeroelasticity of Wind Turbines, Wind Energy, vol. 6, 213-228. https:// doi.org/10.1002/we.98

[72] Longatte, E., Bendjeddou, Z. and Souli, M., Methods for numerical study of tube bundle vibrations in cross-flows, 2003, Journal of Fluids and Structures, vol. 18, 513-528. https:// doi.org/10.1016/j.jfluidstructs.2003.08.010

[73] Souli M. and Zolesio J.P., 2001, Arbitrary Lagrangian - Eulerian and free surface methods in fluid mechanics, Comput. Methods Appl. Mech. Engrg., vol. 191, pp. 451 - 466. https:// doi.org/10.1016/s0045-7825(01)00313-9

[74] J. M. T. Penrose, D. R. Hose, C. J. Staples, I. S. Hamill, I. P. Jones and D. Sweeney, (2000), "Fluid structure interactions: coupling of CFD and FE", 18. CAD-FEM Users' Meeting, International FEM-Technologies

[75] H.K. Versteeg, W. Malalasekera, "An introduction to computional fluid dynamics. The finite volume method”, Longman Scientific \& Technical, New York, 1995.

\section{Author}

Yogesh Ramesh Patel, M.Tech (Mechanical and Material Technology), is with Department of Technology, Savitribai Phule Pune University, Pune, Maharashtra, India. E-mail Id: yogeshpate178270@gmail.com. Ph.No. +91-9403711073.

Article submitted 2020-06-25. Resubmitted 2020-07-24. Final acceptance 2020-07-25. Final version published as submitted by the authors. 